\title{
O currículo das licenciaturas em artes visuais no Paraná: as interferências do proposto na lei para a formação e atuacão do professor
}

The visual arts teaching curriculum in Paraná: the interferences proposed by regulation on teacher formation and performance

Consuelo Alcioni Borba Duarte Schlichta ${ }^{1}$ Valéria Metroski de Alvarenga ${ }^{2}$ 


\section{Resumo}

Este trabalho objetiva identificar, à luz do materialismo histórico-dialético, as relações intrínsecas entre formação docente e atuação, assim como as assimetrias entre as propostas curriculares e a construção de um novo perfil de professor e de ensino de artes visuais articulados às exigências da contemporaneidade. Os dados apresentados são oriundos das pesquisas de mestrado e de pós-doutorado das autoras, ambos realizados no Programa de Pós-Graduação em Artes Visuais, da Universidade do Estado de Santa Catarina. A partir de metodologia quali-quantitativa, com base em Creswell (2010), mapeou-se a quantidade e localização das licenciaturas no Paraná constatando que o atendimento da demanda educacional da disciplina de Arte na Educação Básica mantémse aquém das necessidades reais. Identificou-se, ainda, que somente $50 \%$ dos cursos estão em consonância, de forma plena, com documentos norteadores e leis que interferem em seus currículos. Tal perspectiva teórico-metodológica indicou que a formação-atuação docente é perpassada pelos princípios de ordem socioeconômica e política que permeiam a práxis educativa contemporânea.

Palavras-chave: Formação e atuação de professores. Artes Visuais. Paraná.

\section{Abstract}

In this paper, aiming at identifying the intrinsic relationship between teacher education and performance, as well as the asymmetries between the curricular proposals and the construction of a new teacher profile and teaching articulated visual arts to the demands of contemporary times, analyzed in the light of historical materialism-dialético, data on Degrees in the state of Paraná Visual Arts. These data come from the master's research and postdoctoral of the authors, both held by Post-Program Degree in Visual Arts of the State of Santa Catarina. From qualitative and quantitative methodology, based on Creswell (2010) mapped the amount and location of degrees in Parana noting that meet the educational demands of Art discipline in basic education remains short of actual needs. We identify further that only $50 \%$ of the courses are in line, fully, with guiding documents and laws that interfere with these curriculum. Such theoretical and methodological perspective indicated that teacher training-acting is permeated by the principles of socio-economic and political order that permeate the contemporary educational practice.

Keywords: Education and action of teachers; Visual Arts; Paraná.

ISSN: 2175-2346

${ }^{1}$ Prof. Dra. adjunta IV da Universidade Federal do Paraná - UFPR.

Curitiba - PR. consuelo.ufpr@gmail.com

${ }^{2}$ Mestre em Artes Visuais (PPGAV/UDESC). Licenciada em Artes Visuais pela UFPR. Professora de Arte pela SEED/PR. valeriametroski@hotmail.com 


\section{INTRODUÇÃO}

Quando se trata da formação e da atuação docente, enquanto dois aspectos indissociáveis, a primeira questão a ser enfrentada é a de seus inúmeros condicionantes históricos que afetam desde a estrutura dos cursos de graduação até as visões sobre a arte e seu ensino, perpassadas por crenças e ideologias próprias dos professores formadores e dos futuros professores de arte. Ademais, como as problemáticas da formação e da atuação articulam-se às reformas políticas decorrentes do modelo de sociedade dominante em nosso tempo: a sociedade capitalista, é imprescindível aprofundar a reflexão sobre esses condicionantes, analisá-los criticamente, se a pretensão é superar a naturalização da fragmentação indivíduo-sociedade, que se estende à fragmentação formação-atuação docente.

Para Marx e Engels (1978, p. 10): "Ao dividir o trabalho, divide-se igualmente o homem, sendo todas as outras potencialidades intelectuais e físicas sacrificadas ao aperfeiçoamento de uma actividade única". Portanto, considerando a divisão social do trabalho e a consequente partilha desigual da atividade material e intelectual, entre diferentes indivíduos, a tese que se impõe aqui é a seguinte: a histórica separação entre saber e trabalho também afeta profundamente a dialética formação-atuação do professor. Da separação entre a formação e a atuação tem origem outras divisões: a separação entre o pensar e a prática, entre os conteúdos específicos e os saberes pedagógicos, o que nos leva a considerar a formação do professor articulada à sua práxis, ressaltando-se as condições históricas dominantes.

Por isso, neste trabalho, com o objetivo de apreender as tensões, os descompassos entre formação inicial e atuação docente em arte, explicitamos uma série de dados oriundos das pesquisas de mestrado e de pós-doutorado das autoras, ambos realizados pelo Programa de Pós-Graduação em Artes Visuais, da Universidade do Estado de Santa Catarina (PPGAV-UDESC), entre os anos de 2013 e 2015, desvelando relações e assimetrias entre as propostas curriculares e a construção de um novo perfil de professor de artes visuais articulados às exigências da contemporaneidade.

Cabe ainda esclarecer que essas pesquisas estão vinculadas ao projeto do "Observatório da formação do professor no âmbito do ensino de arte: estudos comparados entre Brasil e Argentina" (OFPEA/BRARG), que, segundo Fonseca da Silva (2013, p. 5), investiu e tem investido "na sistematização de dados para sustentar um conjunto de pesquisas que trazem em seu bojo a intenção de conhecer e reconhecer a área de Ensino de Arte no tocante à formação de professores". Portanto, essas pesquisas são imprescindíveis para contextualizar estudos sobre a formação docente em artes visuais na perspectiva crítica. Buján (2013, p. 80, tradução nossa) complementa que o projeto do OFPEA/BRARG estimula a consolidação de "[...] redes acadêmicas e o desenvolvimento de programas de cooperação internacional, através de vários projetos, assim será possível lidar com vários problemas e desafios (locais e regionais) que nossas sociedades enfrentam", ${ }^{1}$ além de abranger estudos de diversos condicio-

\footnotetext{
1 Segue o texto original: "[...] de redes académicas y el desarrollo de programas de cooperación internacional que, a través de distintos proyectos, se ocupan de diversas problemáticas y desafíos (tanto locales como regionales) a los que se enfrentan nuestras sociedades."
} 
nantes que interferem decisivamente no desenvolvimento da formação do professor de arte nas universidades, como "[...] políticas públicas educacionais, legislação e normas, estruturas curriculares, financiamento, ofertas de formação na graduação e na pós-graduação, distribuição geográfica, modelos de formação [...]."2 (BUJÁN, 2013, p. 84, tradução nossa).

Nossa metodologia é mista, por conseguinte, possibilita uma compreensão dos aspectos abordados, assim como favorece insights através da combinação das pesquisas quantitativa e qualitativa. Segundo Creswell (2010, p. 238), esta permite uma visão de aspectos mais amplos, via a comparação/relação com o aspecto global/ local. Sendo assim, apresentamos alguns dados referentes ao número de cursos de Licenciatura, bem como dados estatísticos relativos aos professores com formação que atuam na área e, ainda, destacamos algumas falas das entrevistas realizadas com alunos egressos desses cursos. Portanto, o presente artigo estrutura-se da seguinte forma: inicialmente apresentamos aspectos relacionados à complexidade da formação e atuação do professor de arte, interconectados com as políticas públicas educacionais, que se expressam nas leis e diretrizes curriculares que orientam e norteiam os cursos de Licenciatura e a disciplina de arte na Educação Básica. Posteriormente, situamos o estado do Paraná em relação a esses documentos balizadores, junto com algumas ideias/sínteses extraídas das entrevistas realizadas com os egressos dos cursos de Licenciatura, que atuam como professores de arte no estado. O intuito, enfim, é analisar as relações entre teoria e prática pedagógica, à luz das tensões entre o proposto, em termos de políticas públicas voltadas à formação do professor, e a realidade escolar, na atual conjuntura nacional.

\section{INTERVENÇÃO DAS POLÍTICAS PÚBLICAS EDUCACIONAIS NA FORMAÇÃO E ATUAÇÃO DO PROFESSOR DE ARTE}

Segundo Sacristán (2000, p. 109), “[...] a política é o primeiro condicionante direto do currículo3, enquanto o regula, e indiretamente através de sua ação em outros agentes moldadores." Isso significa que as políticas públicas educacionais referem-se às decisões/determinações que o Poder Público toma em relação à educação. Tais condicionantes do currículo, para Sacristán (2000), geram o currículo prescrito, que poderá ser alterado pelo currículo em ação. O autor esclarece que o primeiro currículo diz respeito às normas e orientações do que deve ser abordado e que o segundo faz referência à sua transposição na prática do professor formador. Explica, ainda,

\footnotetext{
2 Segue o texto original: "[...] políticas educativas, legislaciones y normativas, estructuras curriculares, financiamiento, ofertas de formación en grado y pos-grado, distribución geográfica de las ofertas de formación, modelos de formación [...]."

3 Segundo Sacristán (2000, p. 108): "A ordenação do currículo faz parte da intervenção do Estado na organização da vida social. Ordenar a distribuição do conhecimento através do sistema educativo é um modo não só de influir na cultura, mas também em toda a ordenação social e econômica da sociedade. Em qualquer sociedade complexa é inimaginável a ausência de regulações ordenadoras do currículo. Podemos encontrar graus e modalidades diferentes de intervenção, segundo épocas e modelos políticos, que tem diferentes consequências sobre o funcionamento de todo o sistema."
} 
que o professor formador - enquanto um sujeito ativo - interpretará o currículo prescrito conforme sua ideologia e princípios que postula sobre a educação e a vida.

Segundo Vasconcellos (2010), a formação inicial, por si só, não resolverá todas as lacunas que abrange, contudo, ao menos, pode-se "[...] discuti-la, analisá-la, colocando em debate os paradigmas da sociedade capitalista brasileira, a política educacional, a profissão professor e a cultura escolar, com suas normas, currículo (oficial e oculto) e especificidades histórico-sociais." (VASCONCELLOS, 2010, p. 4).

É preciso ressaltar que os cursos de formação inicial também estão sujeitos a leis e diretrizes que os orientam em relação à carga horária mínima e as disciplinas que são consideradas indispensáveis. Entretanto, em geral, esses cursos têm autonomia em relação à sua estrutura curricular e promovem mudanças de acordo com os interesses internos e externos às instituições que movem a educação e chegam até corpo docente. Este, por sua vez, é constituído por professores que apresentam linhas teóricas e ideologias diversas, interferindo, assim, no seu conjunto estrutural. Porém, esses discursos e as linhas teóricas que perpassam as práticas educativas dominantes não são esferas excludentes.

Diante desse quadro, Hillesheim (2013), acompanhando reflexiva e criticamente a formação inicial do professor de arte no Brasil, ao analisar pesquisas acadêmicas (teses e dissertações) realizadas na última década, destaca quatro premissas que perpassavam esses estudos, e que podem ser assim resumidas: (i) é preciso provar que a arte é importante; (ii) um bom ensino de arte não deve legitimar os interesses da classe dominante; (iii) é necessário cautela diante das políticas públicas; e (iv) é preciso optar: ou ensinamos arte ou pesquisamos sobre ensino de arte.

Destacando-se a terceira premissa, que revela a desconfiança dos pesquisadores em relação às políticas públicas, explica:

[...] Não sem razão, as pesquisas da área de formação de professores são, a nosso ver, diretamente afetadas por esta terceira premissa, quando sistematicamente questionam os documentos oficiais, investigam sua origem, contrapõem versões e analisam o contexto em que foram construídos. A desconfiança diante das políticas públicas e seus respectivos documentos norteadores e marcos legais converge em pesquisas que evidenciam atitudes vigilantes e cautelosas. (HILLESHEIM, 2013, p. 37).

$\mathrm{Na}$ verdade, ainda que concordemos que cautela é sempre necessária, sobretudo quando se trata do alcance das proposições do Estado brasileiro, tentamos extrair as possíveis contribuições dessas políticas. Porém, não se pense que defendemos a priori toda e qualquer imposição legal ou que aceitamos cegamente tudo o que se propõe nos documentos norteadores, sem questioná-los. O que se pretende, a princípio, tomando como exemplo a lei no 10.639/2003 (História e Cultura Afro-Brasileira), que foi complementada pela lei no 11.645/2008 (História e Cultura Afro-Brasileira e Indígena), é problematizar se essas leis e orientações contribuem para uma revisão crítica das concepções de arte e de ensino presentes no currículo dos cursos de Licenciatura em Artes Visuais e na forma de ensinar arte na Educação Básica. Ou será que permanece a histórica contradição entre o discurso e a prática? O discurso de valorização da arte e da cultura, no caso, afro-brasileira e indígena, efetivamente tem ressonância na realidade? 
Antes, porém, o que se quer ressaltar é que também conquistamos direitos, historicamente negados a determinados grupos, a exemplo das leis citadas anteriormente. Além disso, embora o sistema econômico atual, em moldes neoliberais, imponha modelos de educação, as leis e normas também advêm das lutas das minorias. Vê-se, pois, que não se pode desconsiderar o fato de que se trata de um processo contraditório, sobretudo quando diz respeito ao direito à educação, à arte e à cultura. Conforme alerta Saviani (2014, p. 76),

[...] importa distinguir entre a proclamação de direitos e a sua efetivação. A cada direito corresponde um dever. Se a educação é proclamada como direito e reconhecido como tal pelo Poder Público, cabe a esse poder a responsabilidade de prover os meios para que o referido direito se efetive. Eis por que se impôs o entendimento de que a educação é direito de todos e dever do estado.

Deduz-se, pois, que o direito de todos à educação, à arte e à cultura, embora garantido na lei, não se traduz em ações efetivas por parte do Estado. Por exemplo, a universalização da escola, "como forma de converter todos os indivíduos em cidadãos, isto é, em sujeitos de direitos e deveres", conforme argumenta Saviani (2014, p. 76), "pressupõe o acesso aos códigos escritos", no entanto, sua efetivação não se espelha na realidade.

Do mesmo modo, a segunda premissa destacada por Hillesheim (2013, p. 37): "um bom ensino de arte não deve legitimar os interesses da classe dominante", nos leva de volta à velha conhecida separação entre escolas profissionais para os trabalhadores e escola para as elites, ou classe dominante. E ao projeto concebido pela burguesia, que

[...] não passou, nas suas formas mais avançadas, da divisão dos homens em dois grandes campos: aquele das profissões manuais para as quais se requeria uma formação prática limitada à execução de tarefas mais ou menos delimitadas, dispensando-se o domínio dos respectivos fundamentos teóricos; e aquele das profissões intelectuais para as quais se requeria domínio teórico amplo a fim de preparar as elites e representantes da classe dirigente nos diferentes setores da sociedade. (SAVIANI, 2005, p. 232).

Nessa linha, retomando outra premissa destacada por Hillesheim (2013), que explicita uma antiga discussão sobre a "opção": ou bem ensinamos arte ou bem pesquisamos sobre ensino de arte, cabe argumentar que a crença na necessidade de se optar por uma coisa ou outra também contribui para a naturalização das separações entre um tipo de educação para os trabalhadores e outro tipo para os futuros dirigentes, por consequência, entre fazer e pensar.

Não se pode negar, é claro, a interferência das leis e dos documentos tanto na formação quanto na atuação docente. Lembramos, no caso, a Lei de Diretrizes e Bases da Educação Nacional (LDB) nํ 5.692/71, que teve sua contribuição: tornou obrigatória a disciplina de Educação Artística, assim como influenciou no direcionamento dado ao ensino de arte na Educação Básica, à época, entendida como atividade e não como disciplina. A obrigatoriedade foi o sonho que se realizou, mas a polivalência, que tem origem naquele momento, tornou-se o pesadelo dos professores de arte, até hoje. 
Atualmente, a LDB no 9.394/96 institui a obrigatoriedade do ensino de arte como disciplina obrigatória no currículo da Educação Básica e, conforme seu artigo 26, parágrafo segundo: "O ensino da arte constituirá componente curricular obrigatório", nos diversos níveis da educação básica, de forma a promover o desenvolvimento cultural dos alunos." (BRASIL, 1996). Depois, no parágrafo sexto, assim define: "a música deverá ser conteúdo obrigatório, mas não exclusivo, do componente curricular de que trata o I 20 deste artigo." (BRASIL, 1996). Por fim, o Projeto de Lei no 7.032/10 prevê a separação das quatro linguagens artísticas (música, dança, teatro e artes visuais) na Educação Básica.

Mas, na prática, que mudanças ocorreram? De um modo geral, as Licenciaturas são específicas em Artes Visuais, Música, Dança ou Teatro, contudo, uma professora da rede pública de ensino, quando indagada sobre um único professor trabalhar com as quatro linguagens artísticas, disse: "As quatro linguagens não são um cabresto. Mas, se o professor de arte não dispuser todos estes conteúdos aos alunos, quem mostrará?" (Entrevista oral). Aliás, a justificativa de que todos os alunos têm direito aos conteúdos de todas as linguagens é um argumento mais comum do que se imagina. O seguinte relato de uma professora é bem esclarecedor:

[...] Quando eu comecei a atuar, a escola pedia pra gente articular as quatro linguagens, ter uma base, pois isso está nos PCN [Parâmetros Curriculares Nacionais], nas diretrizes, em outros documentos. Acontece que nas diretrizes e nos $\mathrm{PCN}$, a gente tem orientação para trabalhar as quatro linguagens de forma articulada e durante muito tempo eu fiz isso, mas não articuladamente e sim, conforme algumas orientações dos pedagogos, que diziam: "ah, um bimestre você trabalha Artes Visuais, um bimestre você trabalha Música, um bimestre você trabalha Teatro". (Entrevista oral).

O incrível é que o professor, mesmo vitimado pelas precárias condições de trabalho, quase sempre é propositivo, ou seja, embora especialista em apenas uma linguagem artística, muitas vezes tenta dar conta das quatro linguagens artísticas e, ainda, articular essas áreas com a literatura, com as discussões de meio ambiente, degradação do espaço, etc. O que se observou é que o professor lança mão de todos os meios possíveis ao seu alcance, por vezes inimagináveis, para realizar tal desiderato. A fala de uma aluna egressa do curso de Licenciatura em Artes Visuais esclarece-nos a questão:

[...] Eu tentava articular as quatro linguagens, ter uma base, pois isso está nos PCN, nas diretrizes, em outros documentos, mesmo não tendo a formação, o que

4 Este último foi complementado pela lei no 11.769/2008.

5 Tal projeto de lei poderá vir a resolver o problema da polivalência, que tem sido uma questão em pauta nos debates da área sobre formação/atuação docente. Segundo Alvarenga (2013), a ideia central do Projeto de Lei (PL) no 7.032/10 é: (1) uma ementa que prescreverá as linguagens artísticas específicas que deverão ser ensinadas na Educação Básica separadamente, a saber, Teatro, Música, Dança e Artes Visuais; (2) sugere-se que essas linguagens sejam aplicadas, preferencialmente, quando as escolas incorporarem o ensino em período integral, e a sugestão é que as disciplinas de artes sejam no contraturno; e (3) assim que a lei for aprovada em definitivo, as escolas terão cinco anos para se adequar. Considera-se, ainda, que esse PL resolverá, em termos de lei, o problema dos concursos públicos para a disciplina de arte da Educação Básica, pois, em geral, tais concursos não são por linguagem artística específica, desrespeitando e prejudicando o candidato devido a sua formação. 
eu achava totalmente errado. Por isso, hoje, estudando mais, lendo mais a respeito, entendendo que as diretrizes e PCN não são uma verdade absoluta que você tem que seguir, eu vou trabalhar da minha maneira, que é com as Artes Visuais e buscando sim relações com as outras áreas, principalmente agora na contemporaneidade. [...] Eu não preciso trabalhar diretamente com essas outras linguagens que eu não tenho conhecimento. [...] A Música e a Dança eu já me senti um pouquinho mais afastada. Com uma trilha sonora, um trabalho de videoarte, ou cinema, eu não ficava tão conectada. A dança menos ainda. [...] Quando eu fui trabalhar a Dança com os alunos eu não me senti muito bem, senti que eu não tinha compreensão direito do que era aquilo para conseguir repassar. Eu tentei, tentei por causa de alguns pedagogos que falavam que eu era obrigada a seguir planejamentos anteriores de outros professores. Falavam: “oh, nas Diretrizes está aqui, você tem que trabalhar todas as linguagens, tem que pensar isso, esse aqui é o conteúdo programático, então você tem que se basear nisso para fazer o teu planejamento". Então, em alguns momentos eu aceitava isso, mas não totalmente; eu trabalhava mais Artes Visuais [...]. Eu vou dar um direcionamento, um tema e eles podem trabalhar com o que já conhecem, assim como eu fazia quando eu ensinava Teatro, Música e Dança. Muitas vezes, o aluno já sabia tocar um violão, aí eu o deixava trazer e fazer apresentação para a turma. Ou trabalhava muito bem percussão corporal, eu deixava não só ele apresentar como ensinar os próprios colegas. Então, eu não vou ensinar o que eu não sei. Eles se ensinavam e se ajudavam; era o que eu conseguia fazer conforme as orientações dos pedagogos. (Entrevista oral, grifos nossos).

A professora, como se pode apreender na sua fala, tem plena consciência do equívoco de trabalhar as quatro áreas, "mesmo não tendo a formação", mas, por conta das pressões, tenta trabalhar com todas. Hoje, com mais conhecimento, diz ter também plena consciência de que as diretrizes não são uma verdade absoluta, que devem ser seguidas à risca. As saídas, portanto, como se pode depreender, são inúmeras: desde aceitar (porém, não totalmente), continuando a trabalhar mais Artes Visuais, afinal, é sua área de domínio, até deixar "o aluno livre", quando se trata do trabalho com áreas que não domina. Ainda assim, ciente de seu papel, dá um norte para a atividade, quando propõe um "tema para os alunos trabalharem a partir do que já conhecem", como diz que fazia, quando ensinava Teatro, Música e Dança. Por fim, solicitar a um aluno que "sabe" tocar um instrumento ou realizar os passos de um estilo de dança, por exemplo, que faça uma apresentação para turma ou "ensine" os próprios colegas, é outra prática muito comum. Pois bem, mantém-se a problemática: como exigir do professor que trabalhe com as quatro linguagens artísticas desconhecendo-se que, a princípio, quando licenciado, é formado para atuar em uma das quatro linguagens, não na arte ou nas artes em geral?

Resumindo, tanto as leis quanto os documentos norteadores, em geral, refletem modelos e compreensões distintos sobre o lugar do ensino de arte diante de outras disciplinas do currículo, concepções de arte e de formação docente, ora polivalente, ora específica. O discurso, por sua vez, tomando-se a seguinte passagem dos PCN, mantém-se pendular:

O que se observa, então, é uma espécie de círculo vicioso no qual um sistema extremamente precário de formação reforça o espaço pouco definido da área com relação às outras disciplinas do currículo. Sem uma consciência clara de sua função e sem uma fundamentação consistente de arte como área de conhecimento com conteúdos específicos, os professores não conseguem formular um quadro de referências conceituais e metodológicas para alicerçar sua ação pedagógica; 
não há material adequado para as aulas práticas, nem material didático de qualidade para dar suporte às aulas teóricas. (BRASIL, 2001, p. 32, grifos nossos).

Como vemos, ora o problema está no "sistema extremamente precário de formação", ora credita-se à falta de consciência clara do professor sobre sua própria função ou área de conhecimento.

De qualquer modo, as leis ajudam a justificar a existência de cursos de Licenciatura na área de arte e a necessidade da disciplina na Educação Básica. Tais leis e diretrizes curriculares também direcionam e interferem no currículo dos cursos de graduação e atingem a disciplina de arte na Educação Básica, como é o caso das Diretrizes Curriculares Nacionais (DCN) para os cursos de graduação em Artes Visuais, Música, Dança e Teatro separadamente; a lei no 11.645/2008; a lei no 10.436/2002, e as orientações sobre o uso e o ensino das Tecnologias Contemporâneas.

Conforme a lei no 11.645/2008, que institui a obrigatoriedade do ensino de História e Cultura Afro-Brasileira e Indígena: os conteúdos referentes a essa temática "[...] serão ministrados no âmbito de todo o currículo escolar, em especial nas áreas de educação artística e de literatura e história brasileiras." (BRASIL, 2008, p. 1)6. Ora, isso nos leva a pensar: é preciso lançar mão de uma lei para se garantir a mesma visibilidade e valorização da cultura, da arte e da História Afro-Brasileira e Indígena, destinadas à produção artística, cultural, histórica, europeia e estadunidense, que são hegemônicas? Em primeiro lugar, em nosso entendimento, a lei no 11.645/2008 é uma ação afirmativa e uma forma de resistência à discriminação, desafiando-nos a rever a história da arte "oficial", a ideia de uma única arte ou cultura ou de suas definições atemporais. Aliás, lembrando os argumentos de Canclini (1984), não há como abarcar máscaras africanas, instalações, livros de arte, esculturas modernistas, enfim, uma série de objetos tão diversos em uma única definição de arte. Conforme esclarece o autor,

[...] ao desconectar as obras de arte das suas condições de produção e recepção, podia-se imaginar que eram sempre iguais a si mesmas, que seu sentido não variava ao mudar de classe social ou cultural. Essa universalidade abstrata nunca existiu na realidade e só alcançou certa vigência, nos últimos séculos, pela imposição dos padrões estéticos europeus e norte-americanos aos países dependentes. (CANCLINI, 1984, p. 8).

Desse modo, longe de uma definição atemporal, que desconsidera as condições de produção, distribuição e consumo da arte e da cultura que em cada sociedade constituem os significados dos bens materiais ou simbólicos, é preciso colocar a pergunta em termos sócio-históricos e problematizar: "o que faz de um objeto uma obra de arte e permite diferenciá-lo dos demais objetos"? (CANCLINI, 1984, p. 10). É necessário explicitar que a produção da arte, o que é distribuído, o que chega para consumo da maioria, tudo está em relação de interdependência com o modelo de sociedade, submetido à lógica das relações capitalistas de produção. Aliás, como

6 Anteriormente a essa lei, há a lei no 10.639/2003. O movimento negro continua utilizando-a em separado desta por entender que, ao misturar as duas demandas em uma única lei, o tema da educação afro-brasileira perde a força. É importante ressaltar, também, que mesmo a atual LDB utilizando a palavra arte desde 1996, a lei no 11.645/2008 ainda utiliza a denominação "educação artística" para tratar da disciplina de arte na Educação Básica. 
bem esclarece Canclini (1984, p. 8), não se pode esquecer que:

Junto com a dominação econômica, os países imperialistas impuseram sua concepção estética a quase todas as culturas contemporâneas, e chegaram até a estendê-la ao passado: nos museus reuniram - como se se tratasse da mesma coisa - objetos de povos diferentes, e com aqueles de que não se puderam apropriar, fizeram "museus imaginários", reproduzindo-os nas páginas das histórias da arte. Assim, os produtos mais diversos de todas as épocas foram ordenados, num único sistema, de acordo com a ótica da Europa burguesa.

O que também se quer questionar, concordando com Canclini, é a naturalização da ideia de uma arte ou uma cultura, esquecendo-se que não existe uma única arte ou cultura, ao contrário, segundo Bosi (1992, p. 7), a admissão do caráter plural da cultura, por exemplo, "é um passo decisivo para compreendê-la como um 'efeito de sentido', resultado de um processo de múltiplas interações e oposições no tempo e no espaço". Sim, plurais, como bem resume Bosi, contudo nossa arte e cultura não são caóticas.

Esta questão, em segundo lugar, leva-nos a uma reflexão sobre os conhecimentos relativos ao campo da História da Arte, assim como à crítica aos métodos tradicionais de seu ensino. Contudo, muitas vezes, os discursos permanecem na mera negação da velha História da Arte e na proclamação da nova História da Arte, não se evidenciando uma profunda e rigorosa compreensão de seu conteúdo e da forma de abordá-la.

A fala de uma das professoras entrevistadas, quando inquirida sobre os conhecimentos relativos à História e a Cultura Afro-brasileira e Indígena apreendidos ao longo de sua formação, nos dá bem a dimensão das dificuldades que tem enfrentado tanto a escola quanto as instituições formadoras.

Eu sei que existe uma lei que obriga que esse conteúdo seja trabalhado em sala de aula, mas eu não tive História da Arte e Cultura Afro-brasileira e Indígena. Isso eu não tive na graduação. Não no Paraná, na UFPR não tem. E não sei se tem previsão para ser colocado, porque na verdade não é uma lei que obriga o curso de licenciatura a colocar essa disciplina na grade, mas é uma exigência da Educação Básica, ou seja, se o curso de licenciatura tem que formar o professor para atuar em várias áreas da educação, inclusive na Educação Básica, esse é um conteúdo que deveria ser contemplado na grade. Na escola, os pedagogos pediram pra eu trabalhar História e Cultura Afro-brasileira e Indígena e eu não sabia por onde começar porque eu não tive isso na graduação. (Entrevista oral, grifos nossos)

Para essa professora, levando em conta os problemas pertinentes as escolhas, aos recortes propostos na disciplina:

Em relação à História da Arte, na parte teórica, em alguns momentos algumas questões foram aprofundadas, em alguns momentos não, mas eu acredito que, tirando o fato de não ter tido o conteúdo de História da Arte antes do Renascimento, foi razoável sim, pra ter uma base, pra passar pros alunos, foi razoável sim. Mas, eu lembro que o professor justificou o porquê dele começar a partir do Renascimento, porque trabalhando o Renascimento você tem que voltar lá pra arte Greco-Romana, você tem que fazer links, com o antes, na Idade Média. Então de certo modo você faz esses links com o que ocorreu anteriormente, talvez não do jeito que você gostaria que fosse trabalhado e abordado, mas sempre está pensando nesses outros conteúdos. (Entrevista oral, grifos nossos). 
Como bem demonstra a fala desta professora, são muitos os apelos no sentido de uma qualificação que torne o professor capaz de realizar seu trabalho a contento: "uma base de como trabalhar inclusive algumas técnicas". Conforme argumentou: "isso eu consegui adquirir sim pra repassar pros alunos, mas tem uma grande parte que você tem que pesquisar, não dá pra ficar só com o que você adquiriu na graduação". (Entrevista oral, grifos nossos).

Ao perguntar, ainda, sobre quais conteúdos são prioridades e o que julga necessário trabalhar, ela respondeu:

\begin{abstract}
Bem, independente do que eu ache ou deixe de achar, a gente tem, primeiro, Parâmetros Curriculares Nacionais e Diretrizes Curriculares do Paraná com orientações do que deve ser trabalhado, e você tem o conjunto de professores do colégio, assim como o PPP do colégio que vai te dar os direcionamentos. Então independente do que você ache importante ou relevante, você tem que pensar um pouco nisso para daí colocar a sua experiência de vida e de atuação docente em cima. Então, por exemplo, em relação ao que tem de base no PCN e nas DCE, a gente vai ter uma instrução na área da visualidade para trabalhar com História da Arte, em alguns momentos de maneira linear, pensando desde a pré-história até a arte contemporânea, mas se você vai querer trabalhar aprofundadamente todos esses pontos você nunca chega em arte contemporânea.
\end{abstract}

Em se tratando da História da Arte, o que mais nos chamou a atenção é o fato de que crianças demonstram um enorme entusiasmo diante das imagens, querem admirá-las, ver seus detalhes. Daí a necessidade de um ensino de História da Arte em sintonia com o estudo das imagens, superando-se a antiga atitude contemplativa frente à produção artística, enfatizando-se a interdependência do ponto de vista do aluno articuladamente ao ponto de vista do artista.

Cabe, portanto, valorizar uma prática pedagógica fundamentada no contato com a produção cultural, que inclui, mas excede as obras da História da Arte. Salientamos, pois, a necessidade da escola tornar habitual, desde os anos iniciais, o contato sistemático com a produção cultural própria da sociedade em que as crianças e jovens vivem assim como de outras sociedades. E mais: aproveitar a curiosidade dos alunos. Uma curiosidade, que se evidencia nas perguntas mais comuns e que evidenciam um olhar, embora descritivo, atento em relação às imagens, a exemplo de algumas persistentes: O que é isto? Quem fez? Quando foi realizada e onde está a obra hoje? Outra questão bem recorrente refere-se ao como, à técnica, quase sempre carregada de dúvidas pelo aluno. É fundamental, pois, que o professor domine os conteúdos, abordando-os de modo gradual e sistemático, afinal, as obras não nascem obras de arte, assim como seus autores não nascem artistas.

O trabalho do professor inclui, sobretudo, uma abordagem dos porquês da arte. Por exemplo, se o aluno vê um quadro que não se encaixa no seu padrão de gosto, muitas vezes, questiona a habilidade do autor; assim, os não-figurativos, os expressionistas, são fortes candidatos aos comentários como: "ele não sabia desenhar" ou "não tinha um modelo 'para copiar'". (PARSONS7, 1992, p. 27). A técnica quase sempre

7 Este autor formula uma hipótese baseada na noção de estágios de desenvolvimento, a partir de quatro tópicos: 0 tema, a expressão, o aspecto formal (estilo e forma), o juízo ou avaliação crítica. Trata ainda de uma lista padrão de perguntas recorrentes, como segue: 1) Descreva-me este quadro; 2) De que é que trata? Acha que é um bom assunto 
é vista como habilidade, maestria e, muitas vezes, para o aluno, os objetos artísticos "consagrados" são provas cabais da habilidade, da capacidade do artista. Evidenciase, assim, que um dos grandes desafios do professor é como abordar, sobretudo as obras de arte moderna e contemporânea, como destacado pela professora na entrevista que chamamos atenção anteriormente. Na Arte Contemporânea, em particular, tendo em vista a necessidade de se dar respostas às indagações dos alunos, cabe ao professor partilhar conhecimentos, construir respostas com seus alunos, que clareiem o como o artista fez, até esclarecer a famosa problemática: por que isso é considerado arte?

Enfim, tornar o ensino pleno de conteúdo, desde o conhecimento dos sistemas hegemônicos de arte até a produção denominada arte popular, por vezes, tratada como menor, esquecendo-se que não são campos separados e que "influenciam-se reciprocamente pela relativa intercomunicação que existe entre as classes sociais nas sociedades modernas". (CANCLINI, 1984, p.50)

Postas essas considerações sobre a importância de um ensino de arte, que inclui também a História da Arte, dos saberes das Histórias e das Culturas Afro-brasileira e Indígena, cabe ainda destacar a lei $n$ ㅇ 10.436/2002 e, depois, o decreto $n$ ㅇ 5.626/2005, que institui a obrigatoriedade do ensino de LIBRAS (Língua Brasileira de Sinais) nos cursos de Licenciatura. Esta é a única lei que aponta para a obrigatoriedade desse ensino, especificamente nos cursos de formação inicial, que atende a um determinado tipo de deficiência, pois, de resto, o que se tem são orientações norteadoras, sem o peso de lei. Como a prática tem comprovado, os professores têm contato com alunos com as mais diversas deficiências, o que torna óbvio que o ideal é que ao longo da graduação sejam preparados para atuarem competentemente. Na verdade, a realidade tem nos mostrado que a responsabilidade, a princípio, tem recaído sobre os ombros do professor, esquecendo-se que a educação implica um esforço conjunto: da instituição escolar, da sociedade civil assim como do governo.

Quanto às DCN dos cursos de graduação em Artes Visuais, seu objetivo é orientar a organização do curso, manifesta no Projeto Político Pedagógico (PPP) e que determina o perfil do formando. Neste sentido, trata das "[...] competências e habilidades, os componentes curriculares, o trabalho de curso, o projeto de iniciação científica, o estágio curricular supervisionado, as atividades complementares, o sistema de avaliação, além do regime acadêmico de oferta [...]." (BRASIL, 2009, p. 1). No entanto, o documento delega a orientação dos cursos de Licenciatura para as DCN da formação do professor para Educação Básica quando se trata dessa habilitação, perdendo, assim, as características da especificidade da formação a partir do ponto de vista da arte. Segundo Fonseca da Silva (2010, p. 8), as DCN dos cursos de graduação em Artes Visuais não diferenciam "[...] a formação artística do professor da do bacharel em Artes." Nesta perspectiva, além de não definirem e delimitarem as características da formação inicial entre as duas habilitações, ainda dedicam pouca atenção às Licenciaturas.

para o quadro?; 3) E as cores? São bem escolhidas?; 4) E a forma? E a textura?; 5) Foi difícil fazer este quadro? ; 6) É um bom quadro? Por quê? Ver: PARSONS, Michael J. Compreender a Arte: uma abordagem à experiência estética do ponto de vista do desenvolvimento cognitivo. Lisboa: Editorial Presença, 1992, p. 17 a 35. 
Sendo assim, diante de tantos agentes reguladores, e alguns justificáveis, será que os cursos de Licenciatura incorporam essas orientações ou exigências em suas matrizes curriculares? Para respondermos essa questão, analisamos as matrizes curriculares, e as ementas das disciplinas, de oito cursos presenciais de licenciatura com a nomenclatura Artes Visuais ofertados por oito Instituições de Ensino Superior (IES) públicas no Paraná, com vistas a identificar a presença ou ausência de três aspectos, a saber: (i) referência às tecnologias contemporâneas; (ii) referência à Lei $\mathrm{n}$ ㅇ 11.645/2008 (História e Cultura Afro-Brasileira e Indígena); (iii) referência à Lei no 10.436/2002 (LIBRAS) e inclusão de pessoas com deficiência.

Com o intuito de identificar o perfil dos cursos de licenciatura em Artes Visuais no Paraná, para selecionarmos os cursos que teriam as matrizes curriculares analisadas, realizamos um levantamento da quantidade de cursos de Licenciatura em Artes Visuais nesse estado. Os dados coletados são oriundos do Ministério da Educação (MEC) e do site das Instituições de Ensino Superior (IES) e referem-se ao ano de 2013. Encontramos 28 cursos e constatamos que, apesar da existência de um número maior de cursos de Licenciatura (24) do que de Bacharelado (4) no estado, eles não são suficientes para suprir a demanda de docentes formados em Artes Visuais para atuar na Educação Básicå .

Segundo o Instituto Nacional de Estudos e Pesquisas Educacionais Anísio Teixeira (INEP), em 2013, no estado do Paraná eram formados em Artes Visuais: apenas 7,1\% dos professores atuantes na Educação Básica, enquanto a porcentagem de formados em dança, teatro e música é ainda menor. Tomando-se esses dados é de se imaginar as dificuldades enfrentadas apenas no âmbito do ensino da arte. Após a realização desse levantamento, selecionamos os oito cursos $^{9}$, cujas matrizes curriculares e as ementas ${ }^{10}$ das disciplinas seriam analisadas. Estes foram identificados por letras do alfabeto para preservar-lhes a imagem.

Depois da análise documental, constatamos que a maioria das IES analisadas oferta o mínimo de disciplinas no que se refere à: (i) inclusão de pessoas com deficiência e LIBRAS; (ii) História e Cultura Afro-Brasileira e Indígena; e algumas não ofertam qualquer disciplina contemplando essas temáticas. As disciplinas sobre as Tecnologias Contemporâneas são contempladas por todas as IES analisadas. Veri-

$8 \mathrm{Na}$ Educação Básica, professores formados nas quatro linguagens artísticas (música, dança, teatro e artes visuais) separadamente, assim como professores formados em cursos polivalentes, podem lecionar Arte. Segundo o INEP, em 2013, no Paraná, havia um total de 14,1\% de professores formados em arte, sendo 7,1\% formados em Artes Visuais. Com base nesses dados, faltam $85,9 \%$ de professores formados em todas as linguagens artísticas para lecionar arte no estado do Paraná, mais especificamente, $92,9 \%$ para suprir a demanda em artes visuais. Se considerarmos um total de $25 \%$ de professores atuando em cada uma das quatro linguagens artísticas ainda seriam necessários 17,9\% de professores formados apenas em Artes Visuais no Paraná.

9 Por necessidade de recorte, os cursos foram selecionados de acordo com os seguintes critérios: (i) obrigatoriamente licenciatura; (ii) ter nomenclatura especificamente em artes visuais, pois durante a pesquisa encontramos cursos de arte no estado do Paraná com denominações diferenciadas e, conforme matrizes curriculares, com claras evidências de formação polivalente; (iii) o curso ser ofertado por IES pública; e (iv) curso necessariamente ofertado na modalidade presencial.

10 Para mais detalhes sobre os conteúdos propostos nas ementas das disciplinas que abordam os três pontos analisados, buscar: "Formação inicial do professor de Artes Visuais: reflexões sobre os cursos de licenciatura no estado do Paraná", dissertação de Alvarenga (2015). 
ficamos que $50 \%$ dos cursos apresentam os três temas na matriz curricular, mesmo que seja apenas uma disciplina para cada tema, enquanto que as demais ofertam um ou outro, mas não todos, tal como se pode observar na tabela 1.

\begin{tabular}{|c|c|c|c|}
\hline $\begin{array}{c}\text { Instituição que oferece o } \\
\text { curso de Artes Visuais }\end{array}$ & $\begin{array}{c}\text { Disciplinas sobre Cultura } \\
\text { Afro-Brasileira e Indígena }\end{array}$ & $\begin{array}{c}\text { Disciplinas sobre LIBRAS } \\
\text { e/ou Inclusão de pessoas } \\
\text { com deficiência }\end{array}$ & $\begin{array}{c}\text { Disciplinas sobre Tecnolo- } \\
\text { gias Contemporâneas }\end{array}$ \\
\hline A & 1 & 1 & 3 \\
\hline B & 0 & 2 & 2 \\
\hline C & 0 & 0 & 9 \\
\hline D & 3 & 1 & 5 \\
\hline E & 1 & 2 & 5 \\
\hline F & 0 & 1 & 1 \\
\hline G & 1 & 2 & 2 \\
\hline H & 1 & 0 & 32 \\
\hline Total & $\mathbf{7}$ & $\mathbf{9}$ & \\
\hline
\end{tabular}

Fonte: Elaborada por Alvarenga (2015) com base nas matrizes curriculares e nas ementas dos cursos analisados.

Do ponto de vista do currículo, o fato de algumas Licenciaturas em Artes Visuais investigados não proporem ou ofertarem pouquíssimas disciplinas sobre inclusão de pessoas com deficiência, História e Cultura Afro-Brasileira e Indígena indica que estes cursos não estão em consonância com as políticas públicas educacionais, o que nos leva a concluir que, nesse caso, o proposto na lei distancia-se da realidade. Também demonstram distância de discussões tão atuais, visto que, quando as inserem, mantêm-se no limite da determinação legal, incluindo apenas uma disciplina sobre cada tema. No entanto, o fato de muitos cumprirem a lei, mesmo colocando apenas uma disciplina na matriz curricular, indica que os cursos de Licenciatura em Artes Visuais do Paraná, em geral, atendem às orientações presentes em documentos balizadores ou nas leis. É importante ressaltar que alguns coordenadores, dos cursos que foram objetos de análise, informaram que as matrizes curriculares estão sendo revisadas, indicando que esse quadro pode mudar em breve. Por outro lado, verificou-se que esses cursos apresentam uma grande quantidade de disciplinas sobre as Tecnologias Contemporâneas, evidenciando que estão em consonância com os avanços tecnológicos da contemporaneidade ou preocupados com as normativas a esse respeito.

No que se refere a análise das ementas das disciplinas sobre as Tecnologias Contemporâneas, observou-se que estas possuem diferentes enfoques, os quais vão desde a valorização da parte mais técnica dos meios à intenção das disciplinas em apresentar apenas conhecimentos introdutórios à temática. Notou-se, ainda, que nem todos os cursos se preocupam em direcionar ou relacionar a temática com o ensino de arte. Foi possível observar, também, que as IES analisadas apresentam uma variação das formas de estudos acerca das tecnologias contemporâneas, indo desde a fotografia e vídeo até conhecimentos mais avançados sobre programas diversos de computadores.

Quanto às ementas das disciplinas sobre História e Cultura Afro-Brasileira e Indígena, verificou-se que há uma inclinação a se focar na parte histórica/social dessas temáticas, abordando aspectos das ações afirmativas, do preconceito e da discrimi- 
nação Compreende-se que tais pontos são necessários, todavia, considera-se que é preciso evidenciar também a arte afro-brasileira e indígena. Mostrar a existência de artistas negros e indígenas, suas poéticas, suas produções artísticas tanto como algo específico de suas culturas quanto encontrar meios/formas de relacioná-las com a arte contemporânea, embora em alguns casos a poética deles derive de pressupostos diferenciados dessa estética tida como hegemônica. Constatou-se, ainda, que o foco maior das disciplinas está na História e Cultura Afro-Brasileira e não na História e Cultura Indígena. Na verdade, esta última é praticamente desconsiderada. No entanto, ao realizar uma leitura do conjunto das ementas de todas as disciplinas (e de todos os cursos analisados) constatamos que essas temáticas aparecem de modo indireto em outras disciplinas da matriz curricular, principalmente nas de cunho pedagógico. $O$ mesmo ocorreu em relação à inclusão de pessoas com deficiência.

No que se refere à lei de LIBRAS'11, a maioria das IES ofertou uma disciplina sobre esse ponto, no entanto, apenas três cursos ofertaram além dessa disciplina, uma sobre inclusão de pessoas com deficiência. Na medida em que a maioria dos cursos não oferta nenhuma disciplina abordando outras deficiências, vê-se que as instituições demonstram pouca preocupação com uma situação real que se apresenta na educação básica. Considera-se que tais cursos deveriam, ao menos, proporcionar e indicar a existência dessa realidade, visto que os egressos, em geral, terão contato com alunos com alguma deficiência.

Evidentemente, pode-se deduzir que a inserção das leis ou orientações norteadoras que tratam sobre a inclusão de pessoas com deficiências ou sobre a História da Cultura Afro-Brasileira e Indígena exige uma formação docente mais abrangente e diversificada. É um primeiro passo, inclusive na direção do fortalecimento do ensino da arte.

Pois bem, em razão do exposto, pode-se considerar que a presença ou não de disciplinas que abordem as três temáticas elencadas afeta a formação inicial do professor de Artes Visuais ou não? O contato com disciplinas afins contribui, contudo, não é suficiente. Para que o futuro professor realize uma leitura ampla e qualificada sobre esses temas é fundamental que se aproprie dessas problemáticas, a luz de uma perspectiva histórica. Assim, retomando nossos pressupostos iniciais, pensar a formação inicial do professor articuladamente a sua atuação, implica considerar a consciência e o conhecimento como produções históricas, por consequência, sociais.

Assim, a consciência não pode ser tomada como uma capacidade inata, nem é resultado de uma simples relação estímulo-resposta, nem construção subjetiva, mas uma produção da sociedade. Da mesma forma, o conhecimento, sendo a expressão de uma dada realidade social, não pode ser nem uma elaboração subjetiva, nem um dado objetivo tomado na sua pura materialidade, mas uma relação social. É na forma como os homens se relacionam entre si que está a origem dos objetos humanos, de modo que a decifração do significado desses objetos não poderá realizar-se plenamente sem a compreensão das práticas sociais que lhes dão sentido (KLEIN, 2000, p.15)

110 objetivo dessa disciplina, em geral, é possibilitar uma noção sobre LIBRAS e fornecer caminhos para que o futuro professor de arte possa buscar, posteriormente, outras fontes e novas formações, acima de tudo a proposta da disciplina visa aprofundar a percepção da cultura surda na escola. 
Nesse sentido, muito mais do que uma simples resposta ao previsto em lei, o conhecimentos dos mecanismos de inclusão (e o seu contrário) de pessoas com deficiência, assim como da História e Cultura Afro-Brasileira e Indígena é também compreensão de práticas sociais assimétricas e é aí que a educação em arte ganha relevância. Sob essa perspectiva, o acesso do futuro professor a essas práticas, na forma de saberes escolares, é importante não por que é algo previsto em lei, mas por que a tarefa da escola e do professor é a socialização desses saberes. Em outras palavras, mais do que saberes exigidos na forma da lei, nas DCN e em outros documentos norteadores, esses conhecimentos são necessários à compreensão da vida humana e social. Assim, no exame dessa problemática, cabe um questionamento final: quais os reflexos da formação inicial na atuação docente dos egressos dos cursos de Licenciatura em Artes Visuais?

\section{CONCLUSÃO: AS RELAÇÕES ENTRE O PROPOSTO NA LEI E A ATUAÇÃO DO PROFESSOR}

Cruzando-se o proposto na lei e a atuação do professor, conforme entrevistas, observa-se que ainda enfrentamos o discurso ideológico de que a saída do círculo vicioso em que estamos inseridos está no professor e na sua tomada de consciência. Esquece-se, entretanto, que os problemas que o professor enfrenta não se restringem a uma questão pura e simples de consciência ou de formação, mas envolvem também questões salariais, condições de trabalho, etc., o que nos leva a destacar, por último, que as políticas educacionais devem ser traduzidas em condições materiais, como se descreve no Currículo Básico de Curitiba (CURITIBA, 1988, p. 25): "prédios escolares em boas condições, material didático, bibliotecas bem aparelhadas, salários dignos, aperfeiçoamento profissional constante, conteúdos e métodos curriculares significativos e relevantes para a clientela atendida".

Além disso, as parcerias, por vezes iniciadas com professores de outras disciplinas, comprovam que o cotidiano escolar pressiona o coletivo dos professores na busca por alternativas de trabalhos interdisciplinares. De acordo com uma professora entrevistada, a prática institucionalizada de se trabalhar todas as linguagens artísticas exige um constante exercício de troca com professores de outras áreas: Música, Teatro, e Dança; por vezes, de diálogo com professores de outras disciplinas. Conforme explicou:

É muito difícil encontrar alguém da área da Dança, mas os professores de Educação Física, ajudam muito. A parceria com os professores de Educação Física é para ampliar as possibilidades de trabalho, sobretudo no quesito dança ou teatro, que exige certa expressão corporal, eu fico sempre com a parte de cenografia e adornos em possíveis apresentações temáticas. (Entrevista oral).

Ao chamar a atenção para as parcerias, nosso intuito é também demonstrar que a dinâmica própria na escola, longe de isolar, exige aproximação. O professor, necessariamente, busca parcerias na escola, especialmente o apoio dos colegas que também trabalham com arte. A professora entrevistada, nesse caso, lembra de uma 
colega, que também atua como professora de arte. Diz a professora entrevistada que a colega tem magistério no Ensino Médio, formou-se em Pedagogia à Distância, depois em Psicopedagogia, realizou uma especialização em inclusão social, mas não tem formação em Artes Visuais, contudo possui certo conhecimento na área da Música, pois realizou cursos de canto. Ela lembra:

A troca de materiais, de ideias de trabalho é constante, a gente se reúne todas as semanas, nas horas para planejamento na escola. Ela é responsável por uma turma durante todo o ano letivo, eu por outra, o que implica certa responsabilidade para ambas na hora de aplicar as quatro linguagens. Mas, o que eu planejo, planejo com ela e ela também. (Entrevista oral).

Ainda comentou que existe uma divisão entre a professora regente e a de Artes: a regente é responsável tanto pela turma, quanto pelas demais áreas de conhecimento, mas, embora as especificidades do trabalho de uma e de outra, ambas são responsáveis pela rotina. Como explicou:

\begin{abstract}
a sala de aula possui uma rotina, que está anexada ao quadro negro: agenda com as tarefas do dia e outras, contagem dos alunos presentes, calendário, leitura, ou seja, livros e outros materiais que os alunos têm disponíveis para ler (e que a professora regente chama a atenção, diariamente), atividade do dia, lanche, recreio, atividade após recreio, saída. Esta é a dinâmica da regente. Na aula de arte, embora uma dinâmica um pouco diferente, também inicia com a verificação das agendas e a contagem dos alunos presentes. (Entrevista oral).
\end{abstract}

Sobre o Teatro, por exemplo, a ex-aluna reconhece que não tem as manhas e trabalha mais a História do Teatro, da Dança. Em relação à dança, leva diferentes estilos de dança, com ênfase na street dance, que os adolescentes adoram. (Grifos nossos). De acordo com essa professora - e o fato de trabalhar as linguagens que desconhece de forma mais teórica - os problemas relacionam-se principalmente com a formação específica, pois, um professor

é formado em Música, outro formado em Teatro, outro em Artes Visuais, outro em Educação Artística. Um quer trabalhar as quatro linguagens ou conforme a formação; o outro quer trabalhar só música, o outro quer trabalhar só teatro.

Na prática, os professores tentam encontrar solução para o trabalho com áreas que não dominam ou que não são especialistas. É o que se explicita na fala anterior. Essa situação contraditória é permanente e o que se observa é também uma tentativa contínua do professor trabalhar com a área de conhecimento, mas também se encontra professores que, segundo essa entrevistada,

inventam de dar aula de artes visuais, por causa do barulho, [por que] não tinha sala, espaço adequado pra ensinar música. Então para eles era mais fácil trabalhar as artes visuais. Assim como eu ensinava um pouco de música, eles ensinavam artes visuais. E teatro a mesma coisa. Então, na hora atividade e no período que os professores se reúnem nos intervalos das aulas, a gente conversava, trocava ideia, trocava referência, material para organizar as aulas. A gente conseguia fazer desse jeito. Mas não sei se é o ideal. Você teria que ficar trabalhando o que você não estudou. (Entrevista oral, grifos nossos).

Depois, em alguns momentos, conforme explica, o grupo "conseguia pensar 
junto algumas coisas, [mas] não tinha, na verdade, como fazer isso, porque, cada um vai trabalhar de acordo com a sua linguagem, ou conforme sua formação". E, embora seu esforço na argumentação favorável em relação ao trabalho com as quatro linguagens e que "tentava se basear nas diretrizes, para organizar esse conteúdo, principalmente aqui do Paraná", afirmou que já disse para as outras professoras de artes: no meu caso eu não vou trabalhar com as quatro linguagens. (Entrevista oral, grifos nossos).

Enfim, muitas das parcerias do professor de arte têm origem na necessidade de resolver problemas, que não são unicamente pessoais e sim de todos os professores que vivem sob a pressão de ter de trabalhar com as quatro linguagens artísticas. Assim, ao contrário dos discursos que culpam o professor ou sua inconsciência como a causa dos males que afligem a educação em arte, é vital por às claras a dinâmica da escola, um espaço com suas contradições, intimamente ligado ao espaço maior: o social evidenciando que a crise não é privilégio da educação. Por isso, concordando com Klein (2000, p. 21),

[...] é fundamental que as pessoas que integram a comunidade escolar se reconheçam como sujeitos da mesma classe social, igualmente vitimados pelos mecanismos de exclusão inerentes ao sistema de organização social contemporâneo que são, em última análise, os verdadeiros responsáveis pelas limitações e dificuldades de cada um, e se aliem na luta pela conquista das melhorias que possam garantir a qualidade do ensino.

Ninguém, incluindo-se o professor, existe à margem das relações sociais de produção da existência, pois, como nos esclarece Marx (1989, p. 21): "Os homens fazem sua própria história, mas não a fazem como querem; não a fazem sob circunstâncias de sua escolha e sim sob aquelas com que se defrontam diretamente, legadas e transmitidas pelo passado. "Enfim, no que se refere especificamente à formação do professor de arte, coloca-se como fundamental o acesso ao conhecimento efetivo sobre a história, a teoria da arte, o domínio técnico ampliado dos meios e processos artísticos, sua vivência e experimentação articuladamente ao conhecimento das políticas públicas, no que se refere especialmente ao ensino de arte; por último, uma fundamentação pedagógica histórica e crítica em conexão permanente com a específica.

\section{Referências}

ALVARENGA, V. M. O projeto de Lei no 7.032/10 prevê linguagens artísticas separadas na Educação Básica: será o fim da polivalência? Linguagens - Revista de Letras, Artes e Comunicação, Blumenau, v. 7, n. 3, p. 261-275, set./dez. 2013.

BOSI, A. Plural, mas não caótico. (Org.). Cultura brasileira: temas e situações. São Paulo: Ática, 1992.

BRASIL. Lei no 9.394, de 20 de dezembro de 1996. Estabelece as diretrizes e bases 
da educação nacional. Brasília, DF 1996. Disponível em: <http://www.planalto.gov. br/ccivil_03/leis/l9394.htm>. Acesso em: 30 maio 2015.

. Secretaria de Educação Fundamental. Parâmetros Curriculares Nacionais: Arte. Brasília, DF: MEC/SEF, 2001. v. 6.

Presidência da República. Lei no 10.436, de 24 de abril de 2002. Dispõe sobre a Língua Brasileira de Sinais - Libras. Brasília, DF 2002. Disponível em: <http:// www.planalto.gov.br/ccivil_03/LEIS/2002/L10436.htm>. Acesso em: 30 jun. 2015.

Presidência da República. Lei no 11.645, de 10 de março de 2008. História da Cultura Afro-Brasileira e Indígena. Brasília, DF 2008. Disponível em: <http://www. planalto.gov.br/ccivil_03/_ato2007-2010/2008/lei/l11645.htm>. Acesso em: 30 jun. 2015.

. Ministério da Educação. Conselho Nacional de Educação/Câmara de Educação Superior. Diretrizes Curriculares Nacionais dos Cursos de Graduação em Artes Visuais, bacharelado e licenciatura. Brasília, DF 2009. Disponível em: <http://portal. mec.gov.br/cne/arquivos/pdf/2009/rces001_09.pdf>. Acesso em: 25 jul. 2014.

Projeto de Lei no 7.032, de 24 de março de 2010. Altera os fj̃ $2 \circ$ e 6ㅇ do artigo 26 da lei no 9.394, de 20 de dezembro de 1996, que fixa as diretrizes e bases da educação nacional, para instituir, como conteúdo obrigatório no ensino de Artes, a música, as artes plásticas e as artes cênicas. Brasília, DF 2010. Disponível em: <http:// www.camara.gov.br/proposicoesWeb/fichadetramitacao?idProposicao=470941>. Acesso em: 10 abr. 2015.

BUJÁN, F. La construcción de un observatorio latinoamericano de la formación de profesores de artes en las universidades. Revista Educação, Artes e Inclusão, v. 8, n. $2,2013$.

CANCLINI, N. G. A socialização da arte: teoria e prática na América Latina. São Paulo: Cultrix, 1984.

CRESWELL, J. W. Projeto de pesquisa: métodos qualitativo, quantitativo e misto. Tradução de Magda Lopes. 3. ed. Porto Alegre: Artmed, 2010.

CURITIBA. Currículo Básico: uma contribuição para a escola pública brasileira. Secretaria Municipal da Educação. Curitiba: Imprensa Oficial, 1988.

FONSECA DA SILVA, M. C. R. Formação de professores de arte e perspectivas de atuação política. In: ENCONTRO REGIONAL DA FEDERAÇÃO DE ARTE EDUCADORES DA REGIÃO SUL, 2.; SIMPÓSIO DA LICENCIATURA EM ARTES VISUAIS, 3., 2010. Anais... 23 a 27 ago. 2010. 
Formação do Professor de Arte: da formação na licenciatura à formação continuada. 2013. Disponível em: <http://www.revista.art.br/site-numero-14/mariacristina-rosa.pdf >. Acesso em: 25 abr. 2014.

HILLESHEIM, G. B. D. Um olhar para as pesquisas que abordam a formação de professores de artes visuais: caminhos percorridos e a percorrer. Dissertação (Mestrado em Artes Visuais) - Universidade do Estado de Santa Catarina, Centro de Artes, Florianópolis, 2013.

KLEIN, L. Cadernos da Escola Guaicuru. Elaboração da Proposta Pedagógica para o Ensino Fundamental Ciclo I e II. Secretaria de Estado de Educação de Mato Grosso do Sul, MS, 2000. Disponível em: <http://http//www.educar.ms.gov.br>. Acesso em: 09 set. 2015.

MARX, K.; ENGELS, F. Crítica da educação e do ensino. Introdução e notas de Roger Dangeville. Lisboa: Moraes, 1978.

MARX, K. Manuscritos Econômico-Filosóficos. Lisboa. Edições 70, 1989.

SACRISTÁN, J. G. O currículo: uma reflexão sobre a prática. Tradução de Ernani F. da F. Rosa. 3. ed. Porto Alegre: Artmed, 2000.

SAVIANI, D. Educação socialista, pedagogia histórico-crítica e os desafios da sociedade de classes. In: LOMBARDI, J.; SAVIANI, D. (Orgs.). Marxismo e educação: debates contemporâneos. Campinas: Autores Associados: HISTEDBR, 2005.

O lunar de Sepé: paixão, dilemas e perspectivas na educação. Campinas: Autores Associados, 2014.

VASCONCELLOS, Sônia Tramujas. As mudanças nos cursos de formação de professores de artes visuais: entre claridades e sombras. In: Anais do I Encontro do Grupo de Pesquisa em Arte, Educação e Formação Continuada. p. 1 - 8. Faculdade de Artes do Paraná, Curitiba/PR, 2010. 


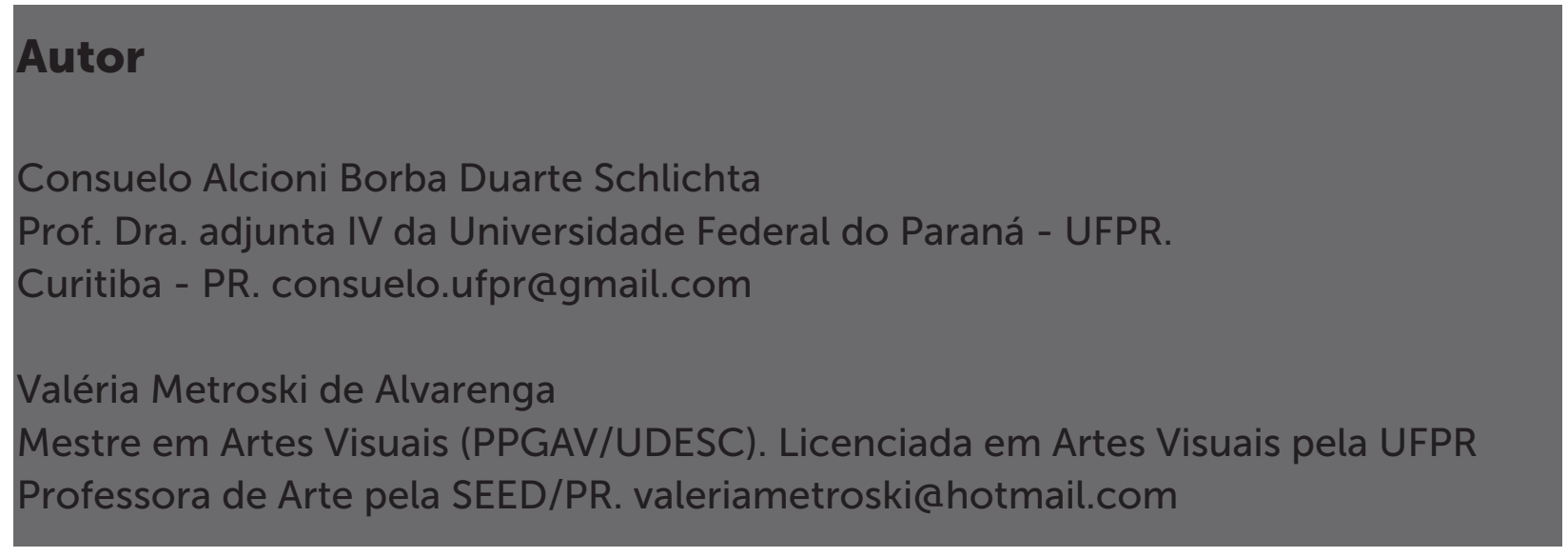

Consuelo Alcioni Borba Duarte Schlichta; 